\title{
Physico-chemical and rheological properties of plain yogurt made from goat's milk during refrigerated storage
}

\author{
Dinushika Suraweera ${ }^{1}$ and Sukanya Wichchukit $^{1 *}$ \\ ${ }^{1}$ Kasetsart University (Kamphaeng Saen campus), Department of Food Engineering, Faculty of \\ Engineering, Kamphaeng Saen, Nakhon Pathom 73140, Thailand.
}

\begin{abstract}
This study aimed to evaluate the effects of the addition of culture on the physico-chemical and rheological characteristics of plain set goat milk yogurt during four weeks of refrigerated storage. Three goat milk yogurt formulations were prepared, each varying the type of culture used (ABT5, ABY3 and YC380). There were significant differences in the $\mathrm{pH}$ values, titratable acidities, moisture content, total solids and percentage syneresis values of all formulations during the storage. All yogurts exhibited shear thinning (thixotropic) flow with different time-independent models for the upward and downward curves. Their viscoelastic behaviour firmly confirmed their weak gel structure that deteriorated during storage time.
\end{abstract}

\section{Introduction}

Goat milk is represented by a minor percentage of the total milk production in the world. Due to the uniqueness of goat milk, it is increasingly getting attention for new product development during the last few years [1]. Goat milk is mainly composed of total solids, protein, fat, lactose and ash. However, the amount of protein content is higher and lactose content is lower in goat milk than in cow milk. Conjugated linoleic present in goat milk has shown to have several protective effects on health such as antioxidant, anti-inflammatory, anti-carcinogenic, anti-adipogenic, antidiabetic, antihypertensive, anti-obesity and antiatherogenic properties [2]. Goat milk can be used to prepare many dairy products such as cheeses, yogurt, dairy beverages, kefir, and ice cream.

Yogurt is traditionally produced by the action of two strains of Lactic acid bacteria Lactobacillus bulgaricus and Streptococcus thermophilus in milk. Codex currently defines yogurt as a milk product obtained by fermentation using Lactobacillus bulgaricus and Streptococcus thermophilus with or without addition of milk powder, other lactic acid bacteria, and sugar. Depending on the style of the yogurt produced the formulation of the yogurt varies but the main steps for the yogurt production remains the same. The sequence of processing is given in Figure 1. During mix preparation blending is necessary to ensure

*Corresponding author: fengskw@ku.ac.th 
the ingredients get uniformly distributed [3]. Several authors used similar processes with similar conditions in preparation of the goat milk yogurt. Nguyen et al. [6] used milk solution reconstituted by skim milk powder to produce the goat milk yogurt. The mix was heated to $85^{\circ} \mathrm{C}$ for $30 \mathrm{~min}$ and cooled to $43^{\circ} \mathrm{C}$. Then the starter culture was added and incubated until the $\mathrm{pH}$ reached 4.6. The yogurt was stored at $4^{\circ} \mathrm{C}$. Miocinovic et al. [4] heated raw goat milk at $90^{\circ} \mathrm{C}$ for $5 \mathrm{~min}$ and cooled to $43^{\circ} \mathrm{C}$. The starter culture was added, incubated to $\mathrm{pH} 4.6$ and stored at $5^{\circ} \mathrm{C}$. Gursel et al. [5] homogenized the milk at $15 \mathrm{MPa}$ at $70^{\circ} \mathrm{C}$ before heating at $90^{\circ} \mathrm{C}$ for $5 \mathrm{~min}$. The milk used was standardized and fortified before processing. Then the milk was inoculated with the starter culture and incubated until the $\mathrm{pH}$ reached 4.7. Finally it was stored at $5^{\circ} \mathrm{C}$.

Previous researches had mainly focused on improving the textural characteristics of goat milk yogurt. Some methods were goat milk fortified with cow milk and milk protein isolate [4], goat milk yogurt mixture fortified with skim goat milk powder, sodium caesinate, whey protein concentrate and whey protein isolate [5]. In another research [4] concluded that goat milk yogurt cannot be classified as a set type yogurt because of its low textural properties such as firmness, consistency and cohesiveness. The processing conditions of goat milk yogurt should not degrade the textural properties any further [6].

This study was aimed to evaluate the physico-chemical and rheological effect of different yogurt cultures and storage time on goat milk yogurt. The addition of probiotic strains with lactic acid bacteria may change physico-chemical properties of yogurt. The storage time is another factor that affects the textural properties of the yogurt. Overall the physico-chemical and rheological changes of yogurt affect the consumer acceptability of the yogurt.

\section{Materials and methods}

\subsection{Starter cultures}

Three types of commercially available yogurt cultures with claimed health benefits were used. Freeze dried ABY 3 yogurt culture containing Streptococcus thermophilus, Lactobacillus delbrueckii subsp. bulgaricus, Bifidobacterium and L. acidophilus, ABT 5 containing Bifidobacterium Lactobacillus acidophilus and Streptococcus thermophilus and YC-380 culture containing Lactobacillus delbrueckii subsp. bulgaricus and Streptococcus thermophilus were purchased from CHR Hansen Pty Ltd (Bangkok, Thailand) and directly used as starter culture.

\subsection{Yogurt production}

Raw goat milk was obtained from a local farm in Nakhon Pathom province. The raw milk was subjected to heat treatment of $80^{\circ} \mathrm{C}$ for $5 \mathrm{~min}$. The milk was then cooled down to $42^{\circ} \mathrm{C}$ and inoculated with freeze dried cultures according to the producer's recommendation. Three portions of milk were stirred with ABT 5, ABY 3 and YC 380 separately. It was followed by incubation at $42^{\circ} \mathrm{C}$ until a $\mathrm{pH}$ of $4.5-4.6$ was reached. Then the yogurts were put into glass containers closed with plastic lids and stored at $4{ }^{\circ} \mathrm{C}$. 


\subsection{Physico-chemical analyses}

Physico-chemical parameters were measured following first $\left(1^{\text {st }}-2^{\text {nd }}\right.$ day $)$, second $\left(14^{\text {th }}-15^{\text {th }}\right.$ day) and fourth $\left(27^{\text {th }}-28^{\text {th }}\right.$ day) week of storage. The $\mathrm{pH}$ of yogurts were measured weekly using a Sartorius PB-10 digital $\mathrm{pH}$ meter (Sartorius Thailand). Titratable acidity was measured by titrating $5 \mathrm{~g}$ of sample with $0.1 \mathrm{~N}$ sodium hydroxide solution using phenolphthalein as the indicator. The total solids and moisture content of samples were determined by the oven drying method according to AOAC (2012). The fat were determined by the Gerber method and protein content by Kjeldhal method. The syneresis of the yogurt samples was measured gravimetrically. The samples of yogurt were centrifuged and the supernatants will be removed and weighed. The syneresis is then calculated as the percentage of the supernatant weight to yogurt weight [7]. The data was analysed using one way ANOVA and pairwise comparisons were done by Tukey's range test.

\subsection{Rheological analysis}

Rheological analyses were performed in triplicate, in Thermo HAAKE RheoStress 1 rheometer (Karlsruhe, Germany), equipped with cone and plate geometry. Samples stored at $4^{\circ} \mathrm{C}$ was taken for the analysis. The shear stress was recorded at increasing shear rates with an upward flow curve; from 10 to 300/s followed by decreasing shear rates with a downward flow curve; from 300 to $10 / \mathrm{s}$. Shear flow data was measured during second $\left(14^{\text {th }}-15^{\text {th }}\right.$ day) and fourth $\left(27^{\text {th }}-28^{\text {th }}\right.$ day) week of storage. The analysis was done in duplicate. Frequency sweep was also carried out by increasing the frequency from 0.01 to $20 \mathrm{~Hz}$ at a constant shear stress of $1 \mathrm{~Pa}$, which was within the linear viscoelastic range of the samples. The storage modulus $\left(\mathrm{G}^{\prime}\right)$ and loss modulus $\left(\mathrm{G}^{\prime \prime}\right)$ were recorded as a function of frequency during the first $\left(1^{\text {st }}-2^{\text {nd }}\right.$ day), second $\left(14^{\text {th }}-15^{\text {th }}\right.$ day $)$ and fourth $\left(27^{\text {th }}-28^{\text {th }}\right.$ day) week of storage. The analysis was done in triplicate. Shear flow data was fitted to the time dependent mathematical model and analysed.

\section{Results and discussion}

\subsection{Physico-chemical analyses}

As shown in Figure 1 the $\mathrm{pH}$ of all three types of yogurt decreases with the storage time and the titratable acidity increases with time. The YC 380 yogurt showed the highest titratable acidity followed by ABY 3 and ABT 5 yogurt and the $\mathrm{pH}$ was lowest in YC 380 followed by $\mathrm{ABY} 3$ and $\mathrm{ABT}$ 5. The $\mathrm{pH}$ values and titratable acidity displayed trends inversely proportional with each other which were consistent with the findings of previous research [8, 9]. Because of the decrease in $\mathrm{pH}$ by the action of bacteria there is a development of the threedimensional semisolid structure of the yoghurt gel. The colloidal calcium phosphate is dissolved and the of net negative charge on the casein micelles is reduced enhancing the protein attractions and aggregation. Initially Casein micelles covalently bonds with denatured whey proteins, which along with the reduction in $\mathrm{pH}$, leads to a formation of chain through hydrophobic and electrostatic bonds and finally creating the semi solid structure of yogurt [10].

The culture and storage time were both significant in terms of $\mathrm{pH}$ values. According to the manufacturer's data sheet the post acidification was lowest in the yogurt with ABT 5 
followed by ABY 3 and YC 380. This explains the highest $\mathrm{pH}$ value showed by the yogurt containing the ABT 5 culture during the all three storage weeks. The YC 380 yogurt showed the lowest $\mathrm{pH}$ due to the high post acidification. Mani-López, Palou \& López-Malo [11] stated that yogurts fermented only with Lactobacillus delbrueckii subsp. bulgaricus displayed high acidity and therefore probiotic cultures had been introduced to maintain the acidity. Hence, the high acidity by the YC 380 yogurt containing only the starter cultures and the lower acidity by ABT 5 and ABY 3 yogurts containing probiotic bacteria could be explained.

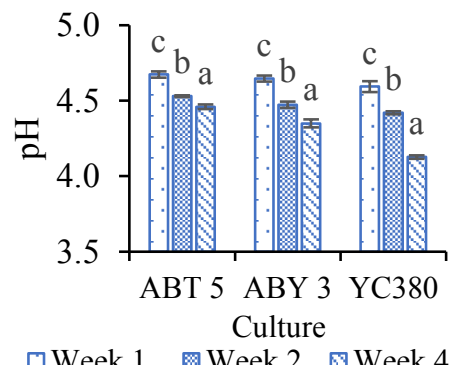

(a)

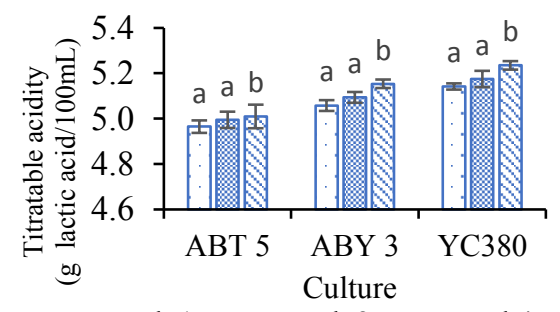

$\square$ Week 1 Week 2 Q 1 Week4

(b)

Fig. 1. Changes in $\mathrm{pH}$ (a) and Titratable acidity (b) of yogurt with storage time.

Lowercase letters indicate statistically significant $(\mathrm{P}<0.05)$ during storage for culture.

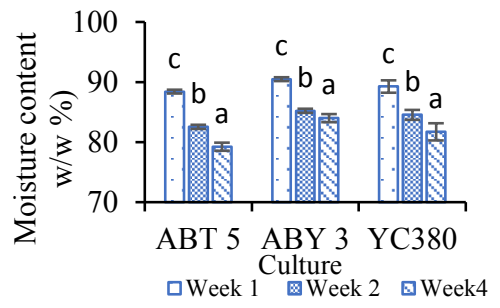

(a)

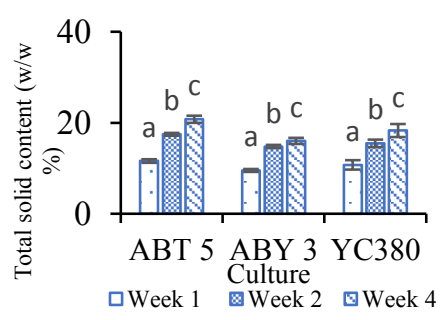

(b)

Fig. 2. Changes in moisture content (a) and total solids content (b) of yogurt with time. Lowercase letters indicate statistically significant $(\mathrm{P}<0.05)$ during storage for culture.

The moisture content differed significantly during storage time and between the cultures. As shown in Figure 2a the moisture content decreases with storage time in all three yogurt samples. Water holding capacity of yogurt is the capacity of yogurt to hold all or part of its own water inside the gel structure. According to Feng et. al [12] the water holding capacity of yogurts lowered on the first 7 days of storage and after that it gradually decreased. As the water holding capacity decreases the amount of free water present increases and therefore this water gets evaporated easily during the oven drying of samples. As shown in Figure $2 \mathrm{~b}$ below, consequently the total solids remaining in the sample increases with the storage time.

Syneresis is one of the important indexes to evaluate the quality of yogurt and is the major visible defect that occurs during yogurt storage. Syneresis usually takes place due to weakening of gel structure and inability of yogurt gel to entrap water phase[13]. Figure 3 shows the changes in the syneresis rates of yogurts added with different cultures. Here, the syneresis rate was expressed as grams of serum phase released per gram of sample. Syneresis of yogurt increased over time. The yogurt containing YC380 culture shows the greatest 
decrease of $\mathrm{pH}$ from 4.59 to 4.13 during storage and the highest post acidification. Owing to the reduction in net negative charge of the casein micelles, it likely resulted in greater whey expulsion. Therefore, it shows the highest syneresis rate. Likewise, the two yogurts containing probiotic bacteria; ABT5 and ABY 3 showed minimal post acidification resulting in a yogurt with weaker coagulum after fermentation. Therefore, less syneresis occurred.

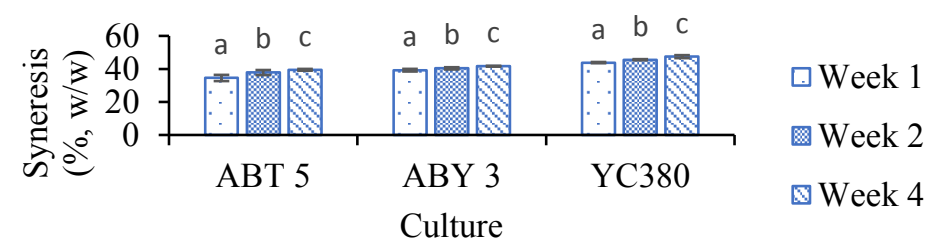

Fig. 3. Changes in percentage syneresis of yogurt with storage time.

Lowercase letters indicate statistically significant $(\mathrm{P}<0.05)$ during storage for each culture.

\subsection{Rheological analyses}

Figure 4 shows flow curves of yogurts during storage time. All yogurts showed hysteresis loops, which indicated time dependent fluids. Lower apparent viscosity values for the downward curves as seen in Figure 5 presents the shear thinning (thixotropic) behaviour. A thixotropic phenomenon was found in many cases of yogurts [14-16] especially the ones using probiotics, a change in apparent viscosity of a fluid is observed when subjected to a constant shear rate. It could be explained that during shearing, the yogurt gel network had tried to resist the shear; however, the breakdown of the network finally occurred after a critical shear rate application [15]. And, the area under the hysteresis loops indicated the breakdown and rebuilding of the yogurt gel network during shearing [16]. The apparent viscosities of yogurt also decreased minutely during storage. The gradual reduction in the apparent viscosity of probiotic yogurt possibly due to the activity of bacteria enzymes on the matrix of casein micelle over the time [17].

The resulting upward and downward flow curves were further fitted to a typical timeindependent model, the Hershel-Bulkley model [18]:

$$
\sigma=\sigma_{0}+K \gamma^{n}
$$

Where $\sigma=$ shear stress, $\sigma_{0}=$ yield stress, $\mathrm{K}=$ consistency index, $\mathrm{n}=$ flow behaviour index, and $\dot{\gamma}=$ shear rate. The resulting model parameters are shown in Table 1. The parameters of the fourth week of storage for the yogurt containing ABT 5 culture were absent due to high fluctuation in raw data. This problem may due to inhomogeneity in the yogurt structure during upward shearing.

phenomenon in these yogurts. However, observing from the time independent model, the yield stress from the upward curve of YC 380 yogurt was consistent during the storage time. 
Table 1. Parameters of the Herschel - Bulkley model for yogurt samples.

\begin{tabular}{|c|c|c|c|c|c|c|c|}
\hline Yogurt & Week & Curve type & $\sigma_{0}$ & $\mathrm{~K}$ & $\mathrm{n}$ & $\mathrm{R}^{2}$ & $\begin{array}{c}\text { Time- } \\
\text { independent } \\
\text { model }\end{array}$ \\
\hline \multirow[t]{2}{*}{ ABT 5} & 2 & $\begin{array}{c}\text { Upward } \\
\text { Downward }\end{array}$ & $\begin{array}{c}0.456 \pm \\
0.913 \\
0.612 \pm \\
0.334 \\
\end{array}$ & $\begin{array}{c}0.721 \pm \\
0.105^{\mathrm{b}} \\
0.016 \pm \\
0.007^{\mathrm{a}} \\
\end{array}$ & $\begin{array}{c}0.344 \pm \\
0.137^{\mathrm{a}} \\
0.964 \pm \\
0.117^{\mathrm{b}} \\
\end{array}$ & $\begin{array}{l}0.995 \\
0.999\end{array}$ & $\begin{array}{c}\text { Herschel - } \\
\text { Bulkley } \\
\text { Bingham } \\
\text { plastic }\end{array}$ \\
\hline & 4 & $\begin{array}{c}\text { Upward } \\
\text { Downward }\end{array}$ & $\begin{array}{c}- \\
0.005 \pm \\
0.004^{\mathrm{a}}\end{array}$ & $\begin{array}{c}- \\
1.188 \pm \\
0.152^{\mathrm{a}}\end{array}$ & $\begin{array}{c}- \\
0.871 \pm \\
0.031^{\mathrm{a}}\end{array}$ & $\begin{array}{c}- \\
0.994\end{array}$ & $\begin{array}{c}- \\
\text { Bingham } \\
\text { plastic }\end{array}$ \\
\hline \multirow{2}{*}{$\begin{array}{c}\mathrm{ABY} \\
3\end{array}$} & 2 & $\begin{array}{c}\text { Upward } \\
\text { Downward }\end{array}$ & $\begin{array}{c}0.000 \pm \\
0.000^{\mathrm{a}} \\
0.894 \pm \\
0.099^{\mathrm{b}}\end{array}$ & $\begin{array}{c}0.589^{ \pm} \\
0.100^{\mathrm{b}} \\
0.017^{ \pm} \\
0.011^{\mathrm{a}} \\
\end{array}$ & $\begin{array}{c}0.458 \pm \\
0.019^{\mathrm{a}} \\
1.057 \pm \\
0.075^{\mathrm{b}} \\
\end{array}$ & $\begin{array}{l}0.996 \\
0.998\end{array}$ & $\begin{array}{c}\text { Pseudoplastic } \\
\text { Bingham } \\
\text { plastic }\end{array}$ \\
\hline & 4 & $\begin{array}{c}\text { Upward } \\
\text { Downward }\end{array}$ & $\begin{array}{c}2.136 \pm \\
0.190^{\mathrm{b}} \\
0.531 \pm \\
0.240^{\mathrm{a}}\end{array}$ & $\begin{array}{c}0.008 \pm \\
0.010 \\
0.018 \pm \\
0.007\end{array}$ & $\begin{array}{c}1.170 \pm \\
0.352 \\
0.994 \pm \\
0.117\end{array}$ & $\begin{array}{l}0.924 \\
0.996\end{array}$ & $\begin{array}{c}\text { Herschel - } \\
\text { Bulkley } \\
\text { Bingham } \\
\text { plastic }\end{array}$ \\
\hline \multirow{2}{*}{$\begin{array}{l}\mathrm{YC} \\
380\end{array}$} & 2 & $\begin{array}{c}\text { Upward } \\
\text { Downward }\end{array}$ & $\begin{array}{c}1.368 \pm \\
0.130^{\mathrm{b}} \\
0.546 \pm \\
0.100^{\mathrm{a}}\end{array}$ & $\begin{array}{c}0.112 \pm \\
0.124 \\
0.015 \pm \\
0.002\end{array}$ & $\begin{array}{c}0.613 \pm \\
0.160 \\
0.928 \pm \\
0.030\end{array}$ & $\begin{array}{l}0.978 \\
0.997\end{array}$ & $\begin{array}{c}\text { Herschel - } \\
\text { Bulkley } \\
\text { Bingham } \\
\text { plastic }\end{array}$ \\
\hline & 4 & $\begin{array}{c}\text { Upward } \\
\text { Downward }\end{array}$ & $\begin{array}{c}1.496 \pm \\
0.240^{\mathrm{b}} \\
0.670 \pm \\
0.100^{\mathrm{a}}\end{array}$ & $\begin{array}{c}0.040 \pm \\
0.012 \\
0.037 \pm \\
0.011\end{array}$ & $\begin{array}{c}0.747 \pm \\
0.039 \\
0.806 \pm \\
0.063\end{array}$ & $\begin{array}{l}0.999 \\
0.999\end{array}$ & $\begin{array}{c}\text { Herschel - } \\
\text { Bulkley } \\
\text { Bingham } \\
\text { plastic }\end{array}$ \\
\hline
\end{tabular}

Lowercase letters indicate statistically significant $(\mathrm{P}<0.05)$ parameters for each culture during each week of storage.

During shearing, the apparent viscosities of yogurt decreased with increasing shear rate (Figure 5) and decreased minutely during storage. Similarly, Aryana and Mcgrew [17] stated that due to the activity of lactic acid bacteria on the casein micelle there is a reduction apparent viscosity with storage time. The viscosities of the three yogurts ranged from $0.02-$ 0.08 Pas and showed not much of a difference among them. The viscoelastic behaviour of yogurts is shown in Figure 6. During the first week of storage, at all oscillation frequencies their storage modulus $\left(G^{\prime}\right)$ was higher than loss modulus $\left(G^{\prime \prime}\right)$, indicating that the elasticity is the dominant property of the yogurt gels. During the second and fourth week of storage, $\mathrm{G}^{\prime}$ was lower than $\mathrm{G}^{\prime \prime}$ indicating that the viscous property is dominant. In the research by Nguyen et. al [6], they stated that the storage modulus $\mathrm{G}^{\prime}$ of the goat milk gel was significantly lower than that of cow and sheep. 


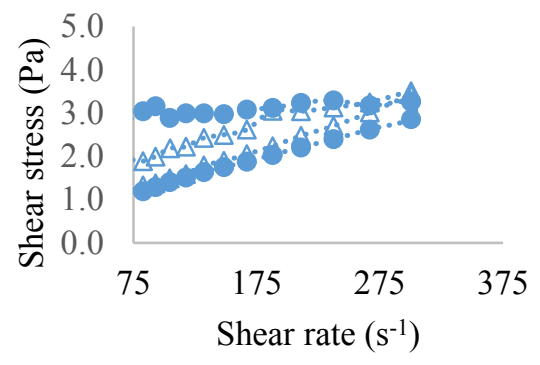

$\ldots$.... Week $2 \quad \ldots . . .$. Week 4

(a)

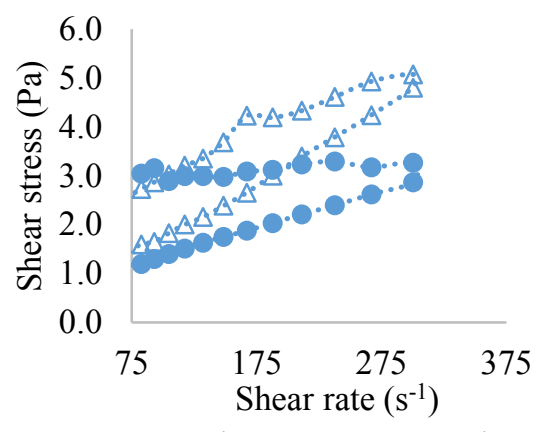

(b)

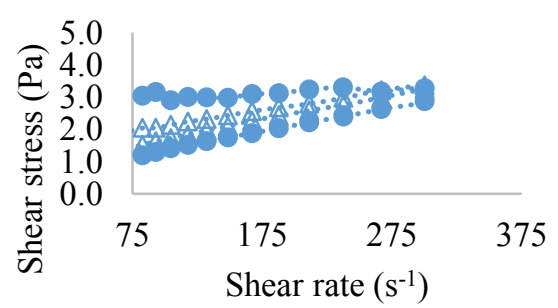

$\ldots$.... Week $2 \quad \ldots \bowtie$.... Week 4

(c)

Fig. 4. Flow curves of yogurt (a) ABT5 (b) ABY 3 and (c) YC 380 cultures with storage time.

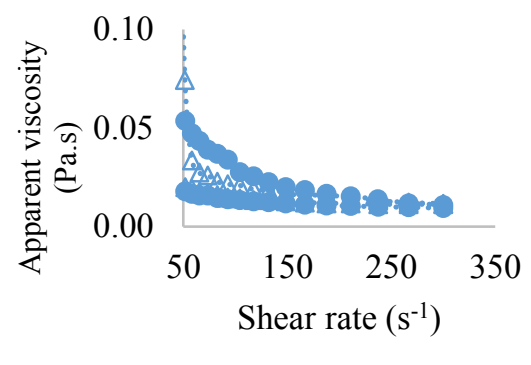

Week 2

(a)

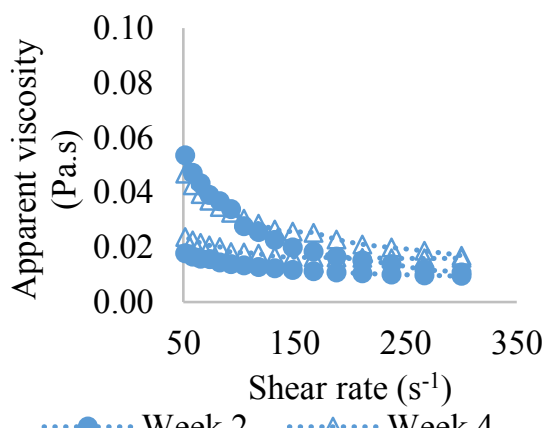

(b)

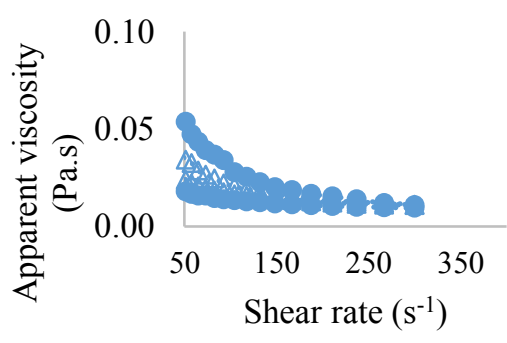

$\ldots$..... Week 2 …

(c)

Aryana and Mcgrew [17] stated that due to the activity of lactic acid bacteria on the casein micelle there is a reduction apparent viscosity with storage time. The viscosities of the three yogurts ranged from 0.02-0.08 Pas and showed not much of a difference among them. The viscoelastic behaviour of yogurts is shown in Figure 6. During the first week of storage, at all oscillation frequencies their storage modulus $\left(G^{\prime}\right)$ was higher than loss modulus $\left(G^{\prime \prime}\right)$, indicating that the elasticity is the dominant property of the yogurt gels. 


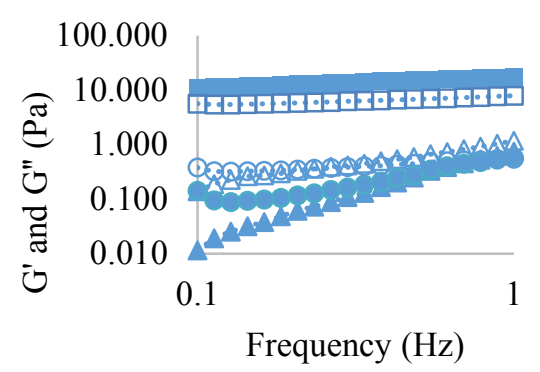

(a)

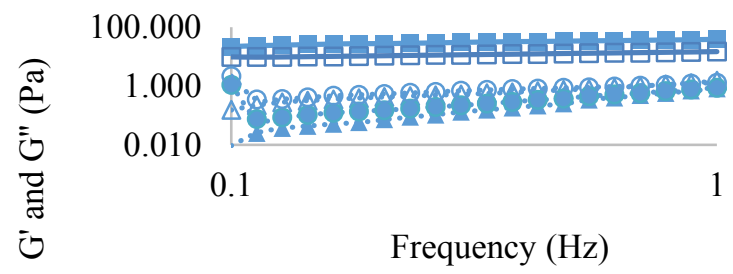

(c)

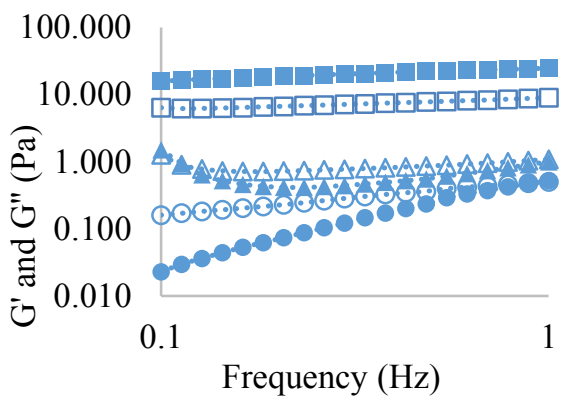

(b)

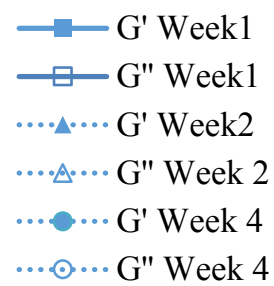

Fig. 6. Frequency dependence of $\mathrm{G}^{\prime}$ and $\mathrm{G}^{\prime \prime}$ for yogurts (a) ABT5 (b) ABY 3 and (c) YC 380 cultures with storage time.

\section{Conclusions}

Yogurts made from different cultures showed significant differences in their physicochemical and rheological properties. The yogurts containing probiotics tended to give weak gel structure and the gel network was less development during storage time due to their low post acidification. All yogurts exhibited shear thinning (thixotropic) flow with different timeindependent models for the upward and downward curves. Their viscoelastic behaviour firmly confirmed their weak gel structure that deteriorated during storage time.

This work was financially supported by the Graduate School of Kasetsart University, Thailand.

\section{References}

1. S. Clark, M. Mora García, J. Dairy Sci. 100, 12 (2017)

2. N. Silanikove, G. Leitner, C. Prosser, Small Rumin. Res. 89, 2-3 (2010)

3. R. Chandan, A. KIlara, Wiley-Blackwell. (2013)

4. J. Miocinovic, Z. Josipovic, A. Nedeljkovic, M. Radovanovic, P. Pudja. Int. Dairy J. 58, (2016)

5. A. Gursel, A. Gursov, E. Anil, S. Aydemir, F. Durlu-Ozkaya, J. Dairy Sci. 99, 4 (2016)

6. H. Nguyen, S. Afsar, L. Day, Food Res. Int. 108 (2018)

7. T. Fang, M. Guo, J. Dairy Sci. 102, 9 (2018)

8. S. Chang, D. Kim, M. Han, Food Sci. Biotechnol. 19 (2010)

9. H. Noh, H. Seo, J. Lee, Y. Chang, Prev Nutr. Food Sci.18, 1 (2013) 
10. W. Lee, J. Lucey, J. Dairy Sci. 87, 10 (2004)

11. E. Mani-López, E. Palou, A. López-Malo, J. Dairy Sci. 97, 5 (2014)

12. C. Feng, B. Wang, A. Zhao et al. Food Chem. 104, (2018)

13. O. Dönmez, B. Mogol, V. Gökmen, J. Dairy Sci. 100, 2 (2017)

14. B. Sah, T. Vasiljevic, S. McKechnie, O. Donkor, J. Food Sci. Technol. 53, 3 (2015)

15. D. da Silva, N. Junior, R. Gomes, M. dos Santon, M. Britten, P. Matumoto-Pintro, J. Food Sci. Technol. 54, 6 (2017).

16. Y. Luo, X. Liu, Z. Pang, J. Dairy Sci. 102, 9 (2019).

17. K. Aryana, P. McGrew, Food Sci. Technol. 40, 10 (2007)

18. J. Steffe Rheological methods in food process engineering, Freeman Press, 1996.

19. P. Morell, I. Hernando, E. llorca, S. Fiszman, Food Res. Int. 70 (2015). 